\title{
Article
}

\section{Carbon dots modified mesoporous organosilica as an adsorbent for the removal of 2,4-dichlorophenol and heavy metal ions}

Wang, Lingzhi, Cheng, Chen, Sen, Tapas, Lei, Juying, Matsuoka, Masaya, Zhang, Jinlong and Zhang, Fan

Available at http://clok.uclan.ac.uk/12357/

Wang, Lingzhi, Cheng, Chen, Sen, Tapas ORCID: 0000-0002-0463-7485, Lei, Juying, Matsuoka, Masaya, Zhang, Jinlong and Zhang, Fan (2015) Carbon dots modified mesoporous organosilica as an adsorbent for the removal of 2,4-

dichlorophenol and heavy metal ions. Journal of Materials Chemistry A, 3 (25). pp. 13357-13364. ISSN 2050-7488

It is advisable to refer to the publisher's version if you intend to cite from the work. http://dx.doi.org/10.1039/C5TA01652E

For more information about UCLan's research in this area go to http://www.uclan.ac.uk/researchgroups/ and search for < name of research Group>.

For information about Research generally at UCLan please go to http://www.uclan.ac.uk/research/

All outputs in CLoK are protected by Intellectual Property Rights law, including Copyright law. Copyright, IPR and Moral Rights for the works on this site are retained by the individual authors and/or other copyright owners. Terms and conditions for use of this material are defined in the policies page. 


\section{ARTICLE}

Cite this: DOI: $10.1039 /$ xoxxooooox

Received ooth January 2012, Accepted ooth January 2012

DOI: $10.1039 / \times 0 \times x 00000 x$

www.rsc.org/

\section{Carbon Dots Modified Mesoporous Organosilica as an Adsorbent for the Removal of 2, 4- Dichlorophenol and Heavy Metal lons}

\author{
Lingzhi Wang ${ }^{1,2}$, Chen Cheng ${ }^{1}$, Sen Tapas ${ }^{3}$, Juying Lei ${ }^{1}$, Masaya Matsuoka ${ }^{4}$, \\ Jinlong Zhang ${ }^{1 *}$, Fan Zhang ${ }^{2 *}$
}

Periodic mesoporous organosilica embedded with carbon dots are adopted as the adsorbent for the removal of toxic organic pollutant 2, 4-dichlorophenol and inorganic metal ions $\mathrm{Hg}$ (II), $\mathrm{Cu}$ (II) and $\mathrm{Pb}$ (II). The composite possesses ordered 2D hexagonal mesostructure with a space group of $p 6 \mathrm{~mm}$, high specific surface area $\left(\sim 468.46 \mathrm{~m}^{2} / \mathrm{g}\right)$ and uniform pore size $(\sim$ $5.50 \mathrm{~nm})$. The surface is covered by about 1-2 layers of carbon dots nanoparticles. The maximum adsorption capacity for 2, 4-dichlorophenol is as high as $99.70 \mathrm{mg} / \mathrm{g}$, and the distribution coefficient of metal ions between adsorbent and solution phases is determined in the range of 2.60-7.41, following the order of $\mathrm{Hg}$ (II) $>\mathrm{Cu}$ (II) $>\mathrm{Pb}$ (II). The $\mathrm{Cu}$ (II) and $\mathrm{Pb}$ (II) adsorptions keep nearly fixed while $\mathrm{Hg}$ (II) adsorption is depressed by $~ 45 \%$ in a mixed metal ions solution. The $\mathrm{Cu}$ (II) and $\mathrm{Hg}$ (II) adsorptions show unobvious variation but $\mathrm{Pb}$ (II) adsorption is improved by $\sim 55 \%$ in mixed metal ion and 2, 4-dichlorophenol solution. In contrast, the presence of different metal ions cause ubiquitously depressed adsorptions of 2, 4-dichlorophenol in the degrees of $37 \%$ (Pb (II)), $45 \%$ (Cu (II)) and $48 \%$ (Hg (II)). The $n-\pi$ electron donor-acceptor interaction between $\mathrm{O}$ - and $\mathrm{N}$ - containing groups of mesoporous organosilica and benzene ring of 2, 4-dichlorophenol is revealed as the main way responsible for the 2, 4-dichlorophenol adsorption, while electrostatic force and complex formation between metal ions and amide groups co-contribute to the metal ions adsorption.

\section{Introduction}

Mesoporous silica is a group of materials with large specific surface area, long-range ordered pore channels, highly tunable pore size and surface chemistry. Since the first invention in $1992^{1}$, they have been widely applied to the pollutants removal ${ }^{2-}$ 5 . However, the adsorption behavior of pollutants on pristine mesoporous silica is comparatively simple, mainly depending on the electrostatic or hydrogen interaction with silanol groups ${ }^{6}$. In consideration of the complex pollutants in the real environment, many efforts have been devoted to tailor the mesoporous structure (space group symmetry, pore size, surface area etc.) and surface chemistry ${ }^{7-9}$. For instance, Yu proposed a kind of novel functional silica microspheres for phosphate removal with high performance even at a very low phosphate concentration ${ }^{10}$. Removals of versatile sewage pollutants have been achieved benefitted from the diverse ways available for characteristics tuning, which complements the existing suite of relatively unspecific conventional sorbents ${ }^{11-14}$.

Besides diversely tunable properties, the eventual application of mesoporous silica for real sewage treatment poses a complicated requirement for the adsorbent from the synthesis, functionalization process and pore ordering. It is desirable to develop a cheap and convenient way to fabricate multiple-group functionalized mesoporous silica adsorbents with ordered pore channel system to meet the demand from the pollutant removal, which still remains a great challenge. Moreover, the current research has mainly focused on the isolate sorption of single metal or organic contaminant by mesoporous silica and ignored any potential interaction between metals and organic contaminants that may influence adsorption process. A singlesolute system may not adequately represent the majority of mixed contaminants commonly encountered in the environment, where complex mixtures of pollutants containing both heavy metals and organic contaminants may coexist at many sites. To the best of our knowledge, the question as whether metals affect the sorption of organic contaminants and vice versa on mesoporous silica has not been adequately addressed ${ }^{15-17}$. The reason for the lack of comprehensive study about the pollutant removal actually lies in the situation that it is still hard to introduce versatile functional groups on mesoporous silica without sacrificing the pore accessibility through a simple synthesis way.

In this study, 2D hexagonal mesoporous silica with a space group of p6mm was synthesized using triblock copolymer P123 as the template and through the co-condensation of silylated carbon dots (CD) $)^{18,19}$ and tetraethylorthosilicate (TEOS). CD is 
chosen since it is a triethoxysilane assembling functional groups of amide and aromatic ring, which is prepared through a fast and convenient pyrolysis process of citric acid and amine-containing silane. This hybrid material possesses specific surface area of $468.46 \mathrm{~m}^{2} / \mathrm{g}$, pore size of $5.50 \mathrm{~nm}$ and pore volume of 0.76 $\mathrm{cm}^{3} / \mathrm{g}$. Besides silanols, the surface is covered with multiple groups of amide and aromatic ring, where the atom weights of $\mathrm{C}$ and $\mathrm{N}$ are $18.3 \%$ and $2.7 \%$, respectively. We applied this multifunctional mesoporous silica to the removal of organic 2, 4dichlorophenol (2, 4-DCP) and inorganic heavy metals including $\mathrm{Cu}$ (II), Pb (II) and Hg (II). 2, 4-DCP was chosen as a model of organic pollutants because chlorophenol derivatives play vital roles as intermediate for the synthesis of dye and pesticide and is hard to be biodegradable. Moreover, the commonly adopted chlorination disinfection process for sewage water further deteriorates the pollution situation caused by chlorophenol derivatives. Heavy metals $\mathrm{Cu}$ (II), $\mathrm{Pb}$ (II) and $\mathrm{Hg}$ (II) commonly exist in the soil environment, especially in soil irrigated by wastewater in the water shortage countries. Previous work has been reported the sorption of metal ions and chlorophenol on mesoporous silica separately ${ }^{20-25}$, whereas in this paper we focus on the competitive adsorption between metal ions, the effect of metals ions on 2, 4-DCP sorption and vice versa, and on the relevant mechanisms in particular.

\section{Experimental}

\section{Synthesis of CD}

Silylated CD nanoparticles were obtained by a one-step hightemperature pyrolysis method described previously ${ }^{19}$. First, 10 mL of $N$-( $\beta$-aminoethyl)- $\gamma$-aminopropyl methyldimethoxy silane (AEAPMS) was heated to $240{ }^{\circ} \mathrm{C}$ under magnetic stirring and nitrogen atmosphere. Then, $0.5 \mathrm{~g}$ of anhydrous citric acid was quickly added into the flask. The mixture was stopped heating after reaction for $1 \mathrm{~min}$, which was then gradually cooled down to room temperature. The CD NPs were obtained by twice washing the crude product with hexane, sealed with hexane and stored in the refrigerator for further use.

\section{Synthesis of CD Modified Mesoporous Organosilica}

CD modified mesoporous silica was prepared by using triblock copolymer Pluronic P123 (EO20PO70EO20, Mav = 5800, Aldrich) as the template, silylated CD and TEOS as the silica co-precursor. Typically ${ }^{26}, 4.0 \mathrm{~g}$ of Pluronic P123 was dissolved in $120 \mathrm{~mL}$ of $\mathrm{HCl}$ solution $(2.0 \mathrm{M})$ to get a homogeneous solution by vigorous stirring at $38^{\circ} \mathrm{C}$. Then, $9 \mathrm{~mL}$ of TEOS and appropriate amount of as-made CD was dropwise added and stirred continually at $38{ }^{\circ} \mathrm{C}$ for $24 \mathrm{~h}$. Then the mixture was transferred into an autoclave and hydrothermally treated at $100{ }^{\circ} \mathrm{C}$ for $24 \mathrm{~h}$. The as-made sample was filtered, washed with deionized water, dried at $60{ }^{\circ} \mathrm{C}$ under vacuum condition. To remove the surfactant, $50 \mathrm{mg}$ of the as-made samples and $60 \mathrm{mg}$ of sodium acetate were added into $5 \mathrm{~mL}$ of ethanol. The mixture was then stirred under reflux at $92{ }^{\circ} \mathrm{C}$ for $1 \mathrm{~h}$, washed and dried. The final product was named as CD-MS.

\section{Batch Adsorption}

Organic 2, 4-DCP and inorganic $\mathrm{Cu}$ (II), $\mathrm{Pb}$ (II) and $\mathrm{Hg}$ (II) ions were adopted as the pollutant models. The solution $\mathrm{pH}$ was adjusted by the addition of $0.1 \mathrm{M} \mathrm{HNO}_{3}$. Adsorption kinetic and thermodynamics experiments were carried out to investigate the adsorption equilibrium time, confirm the adsorption type and assess the adsorption rate. For the study about the isolate adsorption, $60 \mathrm{mg} / \mathrm{L}$ of 2, 4-DCP, 10-3 $\mathrm{M}$ of $\mathrm{Cu}\left(\mathrm{NO}_{3}\right)_{2}, \mathrm{~Pb}$ $\left(\mathrm{NO}_{3}\right)_{2}$ and $\mathrm{Hg}\left(\mathrm{NO}_{3}\right)_{2}$ were prepared and used as a stock solution unless otherwise noted. The adsorbent doses for the isolate adsorptions of metal ions and 2, 4-DCP were 1.0 and $0.2 \mathrm{~g} / \mathrm{L}$, respectively. The mixture was put into the gas bath thermostatic oscillator, and shaken at a certain temperature for $4 \mathrm{~h}$. Then the mixture was centrifuged at $12000 \mathrm{r} / \mathrm{min}$ for $10 \mathrm{~min}$. The obtained liquid was filtered through syringe filters (cellulose acetate membranes) with the size of $0.22 \mu \mathrm{m}$ to remove the particles after the adsorption, and diluted 10 times for the characterization by inductively coupled plasma- atomic emission spectroscopy (ICPAES) or UV-Vis spectroscopy. The adsorption competitions between metal ion and 2, 4-DCP, and different metal ions were investigated in the presence of $1.0 \mathrm{~g} / \mathrm{L}$ adsorbent. For the mixed metal ions and mixed metal ion-2, 4-DCP solutions, the respective concentration of each component remains the same as that in the isolate solution unless otherwise noted.

\section{Characterization}

$\mathrm{X}$-ray diffraction (XRD) patterns were collected in the range of $0.5-5^{\circ}(2 \theta)$ on a RigakuD/MAX 2550 diffractometer using $\mathrm{Cu} \mathrm{K} \alpha$ radiation $(40 \mathrm{kV}, 100 \mathrm{~mA}, \lambda=0.15406 \mathrm{~nm})$. N2 sorption isotherms were measured at $77 \mathrm{~K}$ by a Micromeritics ASAP 2020 analyzer. The Brunauer- Emmett-Teller (BET) method was utilized to calculate the specific surface areas (SBET) by using the Barrett-Joyner-Halenda (BJH) model, the pore volumes and pore size distributions were derived from the adsorption branches of isotherms. The transmission electron microscopy (TEM) was conducted on a JEM 2000EX microscope. 1H 2D DiffusionOrdered Spectroscopy-Nuclear Magnetic Resonance (DOSYNMR) spectrum was performed on a Bruker AM $400 \mathrm{MHz}$ NMR spectrometer. The width of the gradient pulse was $1 \mathrm{~ms}$, and the diffusion time was $150 \mathrm{~ms}$. Fourier Transform Infrared (FT-IR) spectra were recorded from a Nicolet FTIR spectrometer (Nicolet Magna 550). UV-Vis absorption or diffuse reflection spectra were performed on a Scan UV-Vis spectrophotometer (SHIMADZU, $\mathrm{UV}$-2450), with $\mathrm{BaSO}_{4}$ as the reflectance sample. Zata-potential vs. $\mathrm{pH}$ curves were analyzed by a Malvern Zetasizer Nano-ZS instrument (ZEN3600, Malvern Instruments), using $0.1 \mathrm{M}$ of $\mathrm{NaOH}$ and $\mathrm{HCl}$ to adjust the $\mathrm{pH}$ value, and $0.1 \mathrm{M}$ of $\mathrm{NaCl}$ to maintain a high background-electrolyte concentration. The energy dispersive X-ray (EDX) spectrum was performed on an EDAX instrument. High performance liquid chromatography (HPLC, SHIMADZU LC-20A) was used to test the concentration of 2, 4DCP (flow rate: $1 \mathrm{~mL}$ per min, mobile phase: $60 \%$ acetonitrile, column temperature: $40{ }^{\circ} \mathrm{C}$, determine wavelength: $282 \mathrm{~nm}$ ). Water repellency was determined by a contact angle analysis using a contact angle meter (Dataphysic OCA20). The photoluminescence emission spectrum was obtained from fluorescence spectrophotometer (SHIMADZU RF5301-PC). The concentration of metal ions was detected by inductively coupled plasma-atomic emissions spectrometer (ICP-AES, Vanan 710). The peak positions of $\mathrm{Cu}$ ( II ), $\mathrm{Pb}$ ( II ) and $\mathrm{Hg}$ ( II ) were 327, 220 and 253, respectively.

\section{Results}

\section{Structure Analyses}


CD modified mesoporous silica (CD-MS) can be synthesized through the self-assembly of silylated CD, TEOS and triblock copolymer P123 template. The template can be removed by refluxing the as-made sample in the sodium acetate $\mathrm{EtOH}$ solution. The small-angle XRD pattern shows three finelyresolved peaks at $2 \theta=0.92,1.62$ and $1.86^{\circ}$ (Figure 1a), ascribing to the 100,110 and 200 reflections of a $2 \mathrm{D}$ hexagonal mesostructure with a space group of $p 6 \mathrm{~mm}^{27}$. The unit-cell parameter $\left(a_{0}\right)$ is calculated to be $11.76 \mathrm{~nm}$. The transmission electronic microscopy (TEM) image verifies that CD-MS possesses highly ordered parallel-aligned pore channel system (Figure S1).
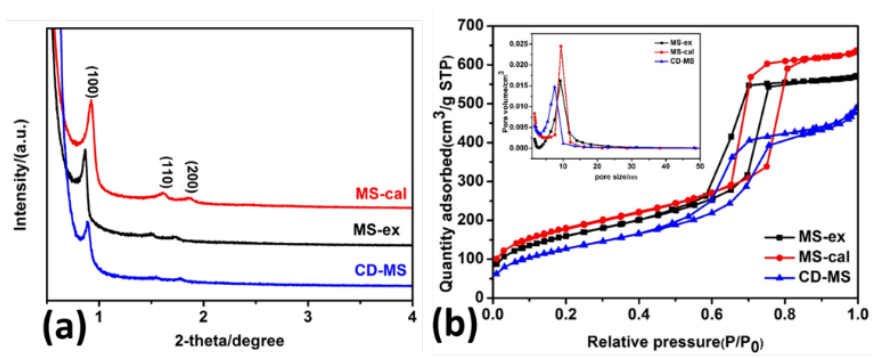

Figure 1: Small-angle XRD patterns (a) and $\mathrm{N}_{2}$ sorption isotherms (b) of MS-cal, MS-ex and CD-MS. Inset is the pore size distribution

The $\mathrm{N}_{2}$ sorption isotherms (Figure $1 \mathrm{~b}$ ) show typical type IV curves with sharp capillary condensation steps and $\mathrm{H} 1$ hysteresis loop in the middle $\mathrm{P} / \mathrm{P}_{0}$ range of $0.5-0.8$, which are characteristic of ordered mesoporous structure and coincident with the results from XRD patterns and TEM image. The specific surface area is calculated to be $\sim 468.46 \mathrm{~m}^{2} / \mathrm{g}$ by Brunauer-Emmett-Teller (BET) method (Table 1). A narrow pore-size distribution curve with the mean value of $\sim 5.50 \mathrm{~nm}$ is obtained from the adsorption branch using Barrett-Joyner-Halenda (BJH) model. The pore volume is about $0.76 \mathrm{~cm}^{3} / \mathrm{g}$. In comparison, the pristine mesoporous silica prepared using TEOS as the single source and through the template-extraction method (MS-ex) has comparable value of $a_{0}(10.19 \mathrm{~nm})$ but increased pore size $(7.78 \mathrm{~nm})$, which becomes even larger $(9.88 \mathrm{~nm})$ when the template is removed by calcination (MS-cal). The particle size of CDs is determined as $\sim 1.0 \mathrm{~nm}$ by ${ }^{1} \mathrm{H}$ 2D DOSY-NMR spectrum (Figure S2). The incorporation of CDs causes an $2.89 \mathrm{~nm}$ increase of the wall thickness and $2.28 \mathrm{~nm}$ decrease of the pore size according to the estimated wall thicknesses of CD-MS $(5.30 \mathrm{~nm})$ and pristine mesoporous silica MS-ex (2.41 nm) on the basis of the hexagonal pore structure, suggesting that the pore surface is covered by 12 layers of CD NPs.

\begin{tabular}{cccccccc}
\hline \multicolumn{7}{l}{ Table 1 Structural and textural parameters of CD-MS, MS-ex and MS-cal } \\
\hline Samples & $\mathrm{S}_{\text {BET }}\left(\mathrm{m}^{2} / \mathrm{g}\right)$ & $\mathrm{V}_{\text {pore }}\left(\mathrm{cm}^{3} / \mathrm{g}\right)$ & $\mathrm{d}_{\text {pore }}(\mathrm{nm})$ & $\mathrm{a}_{0}(\mathrm{~nm})$ & $\mathrm{d}(\mathrm{nm})$ & $\mathrm{d}_{\text {wall }}(\mathrm{nm})$ \\
\hline CD-MS & 468.46 & 0.76 & 5.50 & 11.76 & 10.17 & 5.30 \\
& & & 0.88 & 7.78 & 10.19 & 8.83 & 2.41 \\
MS-ex & 584.87 & 0.93 & 9.88 & 11.40 & 9.87 & 1.52 \\
\hline
\end{tabular}

FT-IR spectra (Figure 2a) of CD-MS show bands at $\sim 3400$, $1650,1450 \mathrm{~cm}^{-1}, 1100$ and $960 \mathrm{~cm}^{-1}$. The bands at $\sim 3400 \mathrm{~cm}^{-1}$ can be assigned to the $-\mathrm{OH}$ stretching from the silanol groups. The presence of $\mathrm{CONH}_{2}$ group is verified by the bands at 1650 and $1450 \mathrm{~cm}^{-1} 17$. The bands at $\sim 1100$ and $960 \mathrm{~cm}^{-1}$ can be assigned to the characteristic $\mathrm{Si}-\mathrm{O}-\mathrm{Si}$ and $\mathrm{Si}-\mathrm{OH}$ vibrations ${ }^{28}$.
The UV-Vis spectrum (Figure 2b) of CD-MS indicates an absorption band centered at $\sim 400 \mathrm{~nm}$, implying the presence of conjugated aromatic ring. The embedding of CD NP increases the isoelectric point from $\mathrm{pH}=2$ for pristine mesoporous silica to $\mathrm{pH}=5$ (Figure 2c), ascribing to the presence of amide group originated from the precursor ${ }^{6}$. The EDX spectrum further confirms the elements of C (18.3 At\%), N (2.7 At\%), Si (33.1 At\%) and $\mathrm{O}$ (45.9 At\%) in CD-MS (At=atom percentage, Figure 2d), which certifies that CD-MS contains rich organic functional groups at another aspect. The fluorescence spectra of CD and CD-MS further verify the existence of conjugated aromatic groups.
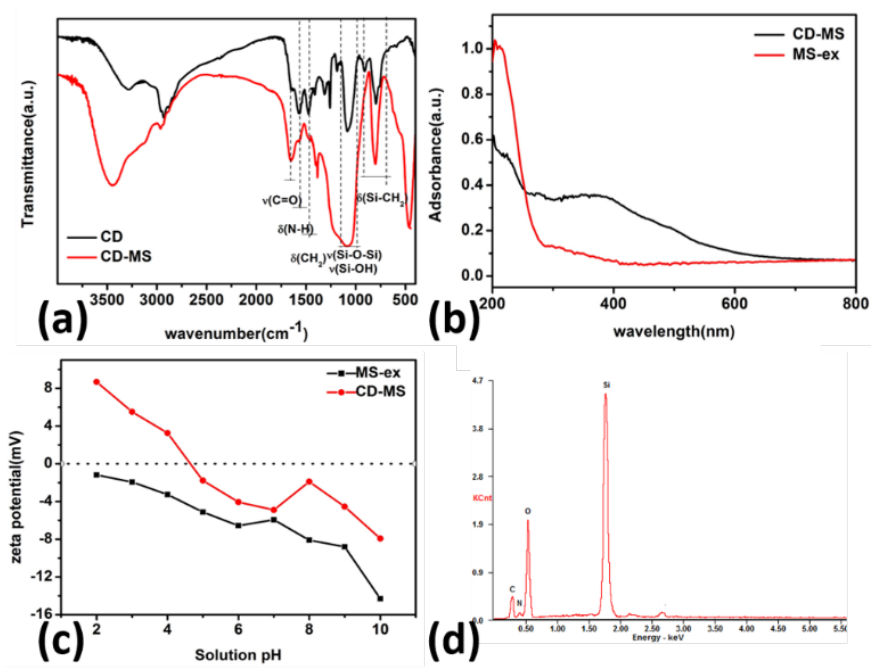

Figure 2: FT-IR spectra of CD and CD-MS (a); Diffuse reflection UV-vis spectra of MS-ex and CD-MS (b); Relation between zeta potential and solution pH of MS-ex and CD-MS (c); EDX spectrum of CD-MS (d).

\section{Adsorption of 2, 4-DCP}

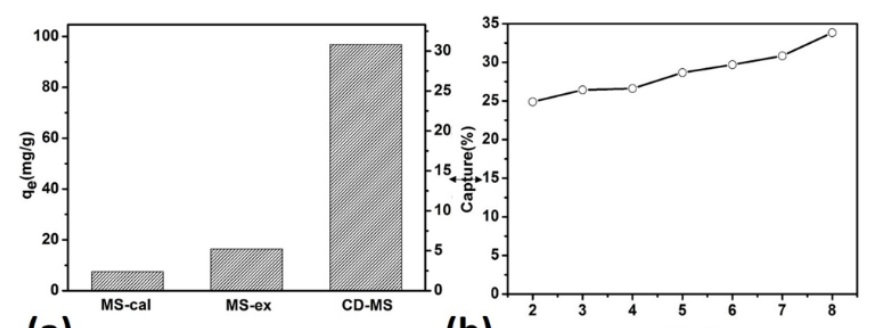

(a)

(b)
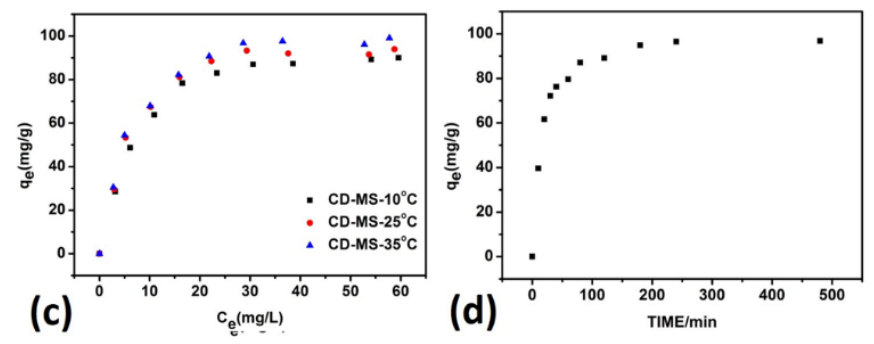

Figure 3: Capture percentages of 2, 4-DCP on MS-cal, MS-ex and CD-MS (a); Effect of solution $\mathrm{pH}$ on 2, 4-DCP adsorption on CD-MS (b); Adsorption isotherms of 2, 4DCP on CD-MS at 10, 25 and $35^{\circ} \mathrm{C}$ (c); Adsorption kinetic curves of 2, 4-DCP on CDMS (d). Adsorbent dose: $0.2 \mathrm{~g} / \mathrm{L}$, contact time: $3 \mathrm{~h}$. (a), (b) and (d) temperature: 10 ${ }^{\circ} \mathrm{C}$, initial concentration of 2, 4-DCP: $60 \mathrm{mg} / \mathrm{L}, \mathrm{pH}=7.0$ 
2, 4-DCP was adopted as the model of organic pollutant due to the high toxicity and hard biodegradability of chlorophenol derivatives $^{21}$. As shown in Figure 3a, CD-MS shows $~ 30 \%$ capture percentage to 2, 4-DCP with an initial concentration of $60 \mathrm{mg} / \mathrm{L}$ at $10^{\circ} \mathrm{C}$, corresponding to a high equilibrium adsorption capacity (qe) of $96.10 \mathrm{mg} / \mathrm{g}$. The adsorption performance is much more efficient than that on MS-ex $(\sim 6.8 \%$, qe $=16.5 \mathrm{mg} / \mathrm{g})$ and MS-cal $(2.5 \%$, qe $=7.5 \mathrm{mg} / \mathrm{g})$. The surfactant in as-made CDMS is removed through solvent-extraction procedure, suggesting that the silanol groups are partly responsible for the improved adsorption. Moreover, the capture percentage prominently decreases with the increasing $\mathrm{pH}$ value of the solution from 2-8, (Figure 3b), indicative of the negative effect of protonation (sorbate and sorbent) on the adsorption behavior ${ }^{30}$. The adsorption thermodynamic data of 2, 4-DCP on CD-MS obtained at $25{ }^{\circ} \mathrm{C}$ (Figure 3c) are simulated by Langmuir and the logarithmic form of Freundlich models, respectively (Figure S4), indicating that the Langmuir model is more suitable to describe the adsorption behavior with the linear coefficient $\mathrm{R}^{2}$ value close to 1 (Table 2, Table S1). In the Langmuir model, it is assumed that all the adsorption sites of the adsorbent have an identical binding energy and each of them binds to only a single layer of adsorbate molecules ${ }^{31}$. In addition, the maximum adsorption amount of 2, 4-DCP increases from 96.81 to $105.5 \mathrm{mg} / \mathrm{g}$ with the increasing temperature from 10 to $35{ }^{\circ} \mathrm{C}$ (Figure 3c, Figure S5, Table 2), revealing the occurrence of an endothermic adsorption process $^{4}$. Data about the adsorption kinetics of 2, 4-DCP on CDMS (Figure 3d) were simulated by pseudo-first-order and pseudo-second-order kinetic models, revealing it is more accordant with pseudo-second-order kinetic model with adsorption equilibrium values close to the measured qe (Figure S6, Table S2) ${ }^{32}$.

Table 2 Thermodynamic constants for the adsorption performance of 2, 4DCP at different temperatures

\begin{tabular}{lccc}
\hline Samples & \multicolumn{3}{c}{ Langmuir model } \\
& $\begin{array}{c}\mathrm{q}_{\mathrm{m}} \\
(\mathrm{mg} / \mathrm{g})\end{array}$ & $\begin{array}{c}\mathrm{b} \\
(\mathrm{L} / \mathrm{mg})\end{array}$ & $\mathrm{R}^{2}$ \\
\hline MS-ex (10) & 16.04 & 0.22 & 0.991 \\
CD-MS (10) & 96.81 & 0.23 & 0.991 \\
CD-MS (25) & 99.70 & 0.27 & 0.992 \\
CD-MS (35) & 105.48 & 0.25 & 0.992 \\
\hline
\end{tabular}

\section{Adsorption performance for metal ions}

$\mathrm{Cu}$ (II), $\mathrm{Pb}$ (II) and $\mathrm{Hg}$ (II) are adopted as models of heavy metal ions. CD-MS shows the capture percentages of $\sim 53,43$ and $56 \%$ to $\mathrm{Cu}$ (II), $\mathrm{Pb}$ (II) and $\mathrm{Hg}$ (II) with the initial concentration of $10^{-3} \mathrm{M}$ (Figure 4a). In comparison, the same pristine mesoporous silica has negligible difference on the capture of these metal ions, but MS-ex presents higher adsorption capacity ( $40 \%$ ) than MS-cal ( $27 \%$ ), indicating the positive effect of silanol groups on the capture of metal ions. The further improved capture ability of CD-MS to metal ions, especially for $\mathrm{Hg}$ (II), should be definitely related to the embedding of CD NPs. The metal ion adsorption on CD-MS is negligible at $\mathrm{pH}=1$, then reaches to the maximum at $\mathrm{pH}=4$, and finally keeps fixing in the $\mathrm{pH}$ range of 4-7 (Figure 4b). The depressed adsorption at acidic solution should be attributed to the protonation of the nitrogenous and siliceous surface of CD-MS with an isoelectric point of 5. Simulations of the thermodynamic adsorption data that collected at $25^{\circ} \mathrm{C}$ and $35^{\circ} \mathrm{C}$ (Figure 4c) by Langmuir and logarithmic form of Freundlich models suggest the Freundlich equation is more reliable than Langmuir model according to the larger correlation factor (0.999), implying the existence of a reversible heterogeneous adsorption and heterogeneity of binding energies of adsorption sites (Figure S7, Table S3). It may be resulted from the different adsorption sites with different metal-binding energies. In addition, all the Freundlich adsorption intensity variables ( $n$ values) are $>1$, following the order of $\mathrm{Hg}$ (II) $>\mathrm{Cu}$ (II) $>\mathrm{Pb}$ (II) (Table 3). In general, isotherm with $n>1$ known as L-type indicates a strong adsorbent affinity for the adsorbate, suggesting $\mathrm{Hg}$ (II) and $\mathrm{Pb}$ (II) have the highest and least affinities to CD-MS. The higher $\mathrm{K}_{\mathrm{f}}$ value of $\mathrm{Hg}$ (II) adsorption further proves a stronger adsorption force due to higher affinity between the amide groups CD-MS and Hg (II). The influence of temperature for different metal ions by CD-MS shows all the $n$ values for three kinds of metal ions decrease with the increasing temperature (Figure 4c, Figure S8, Table S4), revealing an exothermic chemi-adsorption process. Similar to the adsorption process for 2, 4-DCP, the adsorption process for metal ions is also accordant with pseudosecond-order kinetics ( $\mathrm{R}^{2} \sim 1$ ) (Figure 4d, Figure S9, Table 3, Table S3), implying that chemical bonding might be the ratelimiting step ${ }^{33,34}$. The reusability of CD-MS is certified through recycle experiments (Figure S10). The adsorption capacity could be maintained after 4 recycles, indicating the excellent reusability of our adsorbent.
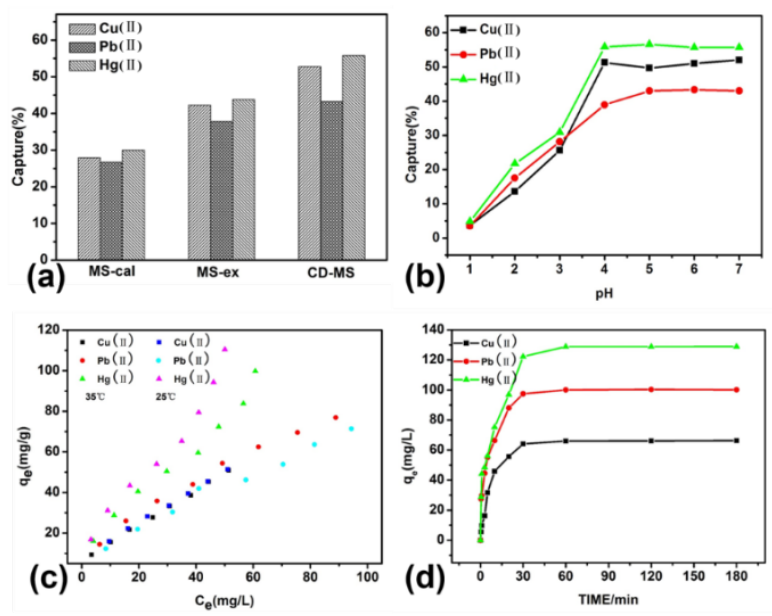

Figure 4: Capture percentages of $\mathrm{Cu}$ (II), $\mathrm{Pb}$ (II) and $\mathrm{Hg}$ (II) on MS-cal, MS-ex and CD-MS (a); Effect of $\mathrm{pH}$ on metal ion adsorption on CD-MS (b); Adsorption isotherms of different metal ions on CD-MS at 25 and $35^{\circ} \mathrm{C}$ (c); Adsorption kinetic curves of metal ions on CD-MS (d). Adsorbent dose: $1 \mathrm{~g} / \mathrm{L}$, contact time: $3 \mathrm{~h}$. Initial concentration of $\mathrm{Hg}$ (II) and $\mathrm{Pb}$ (II): $10^{-3} \mathrm{M}$, (a) and (b) initial $\mathrm{Cu}$ (II) concentration: $10^{-3} \mathrm{M}$, (c) and (d) initial $\mathrm{Cu}$ (II) concentration $2 * 10^{-3} \mathrm{M}$. (a), (b) and (d) temperature: $25^{\circ} \mathrm{C}, \mathrm{pH}=7.0$. 
Table 3 Freundlich isotherm constants and the pseudo-second-order kinetics parameters for the metal ions adsorptions on CD-MS

\begin{tabular}{ccccccc}
\hline \multirow{2}{*}{$\begin{array}{c}\text { Adsorb- } \\
\text { ate }\end{array}$} & \multicolumn{3}{c}{ Freundlich curve } & \multicolumn{3}{c}{ Pseudo-second-order model } \\
& $\mathrm{K}_{\mathrm{f}}$ & $\mathrm{n}$ & $\mathrm{R}^{2}$ & $\mathrm{q}_{\mathrm{e} 2}$ & $\mathrm{k}_{2}$ & $\mathrm{R}^{2}$ \\
\hline $\mathrm{Cu}(\mathrm{II})$ & 3.23 & 1.53 & 0.997 & 68.96 & $2.89 \times 10^{-3}$ & 0.999 \\
$\mathrm{~Pb}(\mathrm{II})$ & 2.60 & 1.38 & 0.993 & 102.35 & $3.40 \times 10^{-3}$ & 0.999 \\
$\mathrm{Hg}(\mathrm{II})$ & 7.41 & 1.55 & 0.974 & 132.98 & $1.78 \times 10^{-3}$ & 0.999 \\
\hline
\end{tabular}

$\mathrm{K}_{\mathrm{f}}\left(\mathrm{mg}^{1-(1 / \mathrm{n})} \mathrm{L}^{1 / \mathrm{n}} \mathrm{g}^{-1}\right)$ is the Freundlich constant about the adsorption capacity of the adsorbents; $\mathrm{q}_{\mathrm{e} 2}(\mathrm{mg} / \mathrm{g})$ is the adsorption capacity at adsorption equilibrium obtained through experiments; $\mathrm{k}_{2}$ (g/(mg.min)) is the kinetic rate constants for the pseudo- second-order models.

\section{Competitive adsorption}

Currently, there is a lack of studies on the competition adsorption of different metal ions, and the influence of metal ions to the sorption of organics and conversely organics to metal adsorption on mesoporous silica adsorbents. Here, CD-MS was further adopted as the adsorbent for the treatment of multicomponent polluted solution. In a mixed $\mathrm{Cu}$ (II)-Pb (II)-Hg (II) system, all the three metal ions display the adsorption behavior well fitted to Freundlich model (Figure 5a, Table 4), proving that the mixed system does not influence the heterogeneous adsorption behavior of respective metal ion. However, compared with the adsorption capacity in isolate component solution, $\mathrm{Hg}$ (II) adsorption suffers $\sim 45 \%$ decrease while $\mathrm{Cu}$ (II) and $\mathrm{Pb}$ (II) adsorption shows negligible variation (Figure $5 b$ ) in the mixed solution. The concentration of respective metal ion in mixed solution is the same as that in isolate solution, leading to the increase of the total metal ion concentration. The preserved adsorption capacity to $\mathrm{Cu}$ (II) and $\mathrm{Pb}$ (II) at least indicates that the mesoporous adsorbent has enough volume to accommodate large amount of metal ions. The reason for the decreasing of $\mathrm{Hg}$ (II) adsorption will be analyzed in the following discussion section.
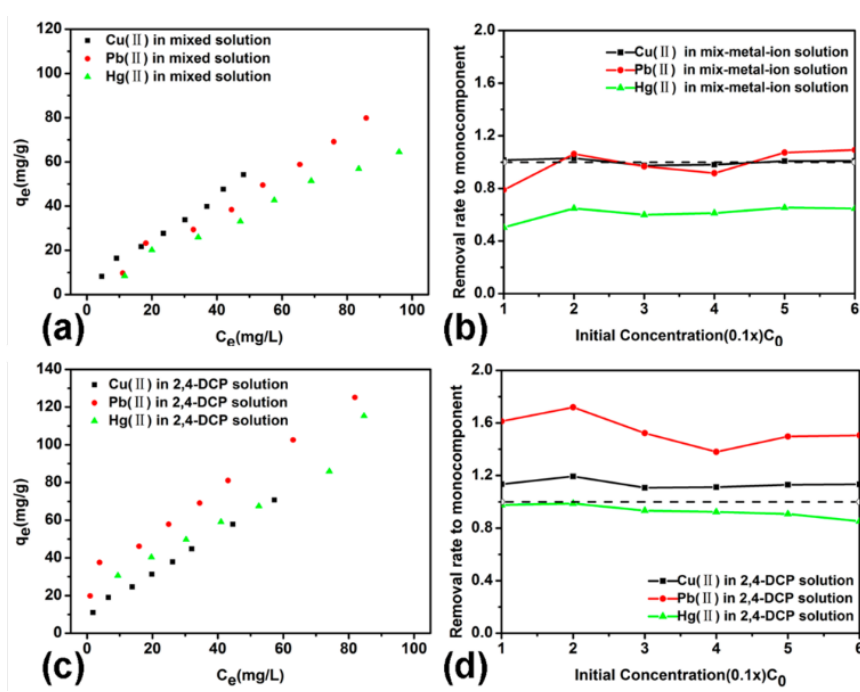

Figure 5 Adsorption competitions in tri-metal ion and metal ion-2, 4-DCP solutions (a); Removal rate of metal ion in tri-metal ion system to mono-component solution (b); Metal ion adsorption in the mixed solution of metal ion-2, 4-DCP (c); Removal rate of metal ions in metal ion-2, 4-DCP mixed solution to mono-metal solution (d). Adsorbent dose: $1 \mathrm{~g} / \mathrm{L}$, contact time: $3 \mathrm{~h}$, temperature: $25{ }^{\circ} \mathrm{C}$, concentration of 2, 4-DCP: $60 \mathrm{mg} / \mathrm{L}$.

In a mixed organics-inorganics system (Figure 5c, d), the presence of 2, 4-DCP $(60 \mathrm{mg} / \mathrm{L})$ does not change the adsorption mode of metal ions, which can still be well fitted by Freundlich model. However, study on the adsorption capacity indicates the presence of 2, 4-DCP leads to averagely $45 \%$ increase of $\mathrm{Pb}$ (II) adsorption in the initial concentration range of $0-80 \mathrm{mg} / \mathrm{L}$. Cu (II) and Hg (II) adsorptions present less than $10 \%$ increase and decrease, respectively. The variation of adsorption capacity of metal ions indicates a complicated competition behavior occurs in the mixed organic-inorganic solutions. In contrast, all of 2, 4DCP adsorptions are depressed when co-existed with the metal ion in the degrees of $37 \%$ (Pb (II)), $45 \%$ (Cu (II)) and $48 \%(\mathrm{Hg}$ (II)) (Figure 6), revealing that the type of metal ions also influences the 2, 4-DCP adsorption.

Table 4 Freundlich constants of metal ion adsorption on CD-MS in tri-metal ion solution and metal ion-2, 4-DCP solution

\begin{tabular}{ccccccc}
\hline & \multicolumn{8}{c}{ Freundlich model parameters } \\
Adsorbate & \multicolumn{1}{c}{ Triple-metal ion solution } & \multicolumn{2}{c}{ Metal ion-2, 4-DCP solution } \\
& $\mathrm{K}_{\mathrm{f}}$ & $\mathrm{n}$ & $\mathrm{R}^{2}$ & $\mathrm{~K}_{\mathrm{f}}$ & $\mathrm{n}$ & $\mathrm{R}^{2}$ \\
\hline $\mathrm{Cu}(\mathrm{II})$ & 2.68 & 1.32 & 0.988 & 3.43 & 1.35 & 0.998 \\
$\mathrm{~Pb}(\mathrm{II})$ & 2.17 & 1.35 & 0.971 & 8.25 & 1.64 & 0.994 \\
$\mathrm{Hg}(\mathrm{II})$ & 1.07 & 1.10 & 0.975 & 5.15 & 1.49 & 0.950 \\
\hline
\end{tabular}

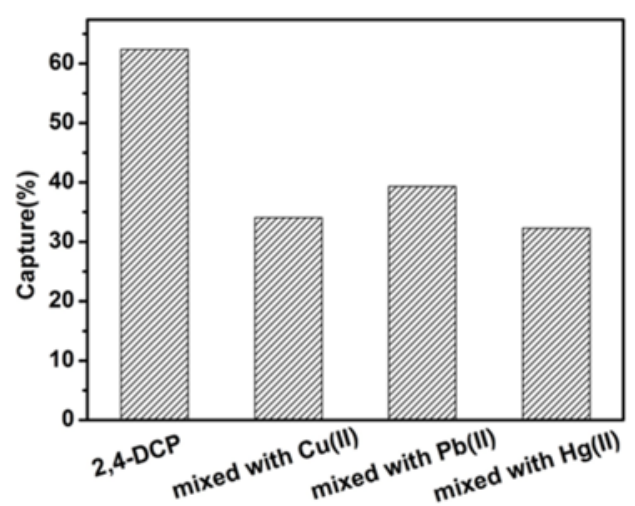

Figure 6 The adsorption of 2, 4-DCP on CD-MS in the presence of different metal ions.

\section{Discussion}

\section{Adsorption on Pristine Mesoporous Silica}

The surface of MS-ex without the high-temperature calcination treatment should be covered with high-density of silanol groups. Compared with MS-ex, MS-cal has less surface silanols due to its more polymerized silicates frameworks from a calcination treatment at $550{ }^{\circ} \mathrm{C}$ for $6 \mathrm{~h}$. The surface of pristine mesoporous silica is dissociated and negatively charged in a neutral environment according to the measured isoeletric point (Figure 2c). As a $\pi$-acceptor compound (i.e., electron-deficient aromatic $\pi$-system) due to the presence of two $-\mathrm{Cl}$ substituent groups, 2, 4-DCP can form $n-\pi$ electron donor-acceptor ( $n-\pi$ EDA) interaction with oxygen atom on silanol groups ${ }^{35}, 36$. Compared with MS-cal, the tripled capture percentage of 2, 4DCP on MS-ex suggests the excellent adsorption performance of CD-MS to 2, 4-DCP is partly attributed to the $n-\pi$ EDA interaction between 2, 4-DCP and oxygen atom on surface silanols since MS-ex and CD-MS are both prepared through template-extraction. The similar capture percentage for different metal ions on MS-cal indicates that the property of different metal ions has no influence to the adsorption behavior. The non- 
differential improvement of capture percentage on MS-ex further verifies the existence of the same adsorption behavior of different metal ions. The adsorptions of metal ions such as $\mathrm{Hg}$ (II), $\mathrm{Cu}$ (II) and $\mathrm{Pb}$ (II) on pristine mesoporous silica are carried out at $\mathrm{pH}=7$. Based on the isoelectric point of pristine mesoporous silica ( $\mathrm{pH}=2$, Figure $2 \mathrm{c}$ ), the adsorption of metal ions should be attributed to the electrostatic interaction between positively charged metal ions and negatively charged siliceous surface of MS-ex and MS-cal at neutral environment. The higher adsorption capacity of MS-ex than MS-cal should be attributed to the more negatively charged surface at neutral environment.

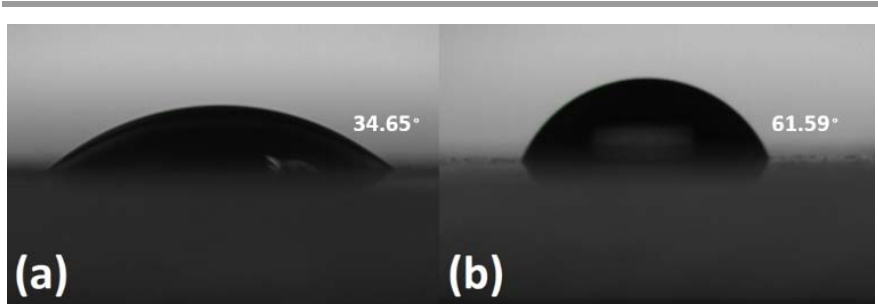

Figure 7 Images of contact angles of (a) MS-ex and (b) CD-MS.

\section{Effect of CD Embedding}

Compared with pristine mesoporous silica, the mesopore surface of CD-MS is covered with multiple groups of silanol, amide and aromatic ring (Figure 2a, b), leading to variable adsorption behavior to different adsorbates. The pronounced improvement of the adsorption capacity observed on CD-MS should be attributed to the high incorporation content of CD containing amide and aromatic ring groups without the deterioration of the pore ordering and accessibility. The hydrophobicity test was further carried out to identify the contribution of hydrophobic interaction due to the presence of aromatic ring in CD. The contact angle increased from $34.65^{\circ}$ for MS-ex to $61.59^{\circ}$ for CD-MS (Figure 7), indicating CD-MS is more hydrophobic than pristine mesoporous silica due to the CD embedding. However, such kind of hydrophobicity seems incompetent to the significant improvement of adsorption capacity as demonstrated in Figure 3a since the surface of CDMS is actually still hydrophilic. In general, hydrophobic interaction refers to the adsorption behavior of aromatic compounds without polar functional groups through weak Van der waals force. As mentioned above, the presence of two electron-withdrawing - $\mathrm{Cl}$ substituents on aromatic ring should produce an electron-deficient $\pi$-systems by removing electron density from 2, 4-DCP. 2, 4-DCP as a $\pi$ acceptor is adsorbed by pristine mesoporous silica through $n-\pi$ EDA interaction, which is verified by the increased adsorption of 2, 4-DCP on MS-ex compared with that on MS-cal due to the presence of higher density of silanol groups on MS-ex. Besides aromatic ring, CDMS also contains amide group, where the $\mathrm{O}$ and $\mathrm{N}$ atoms should also possibly form $n-\pi$ EDA interaction with 2, 4-DCP. However, the binding affinity of $n-\pi$ EDA interaction between 2 , 4-DCP and dissociated silanol groups is stronger than that caused by hydrophobic interaction since the bonding enthalpies involved in hydrophobic interactions are considered negligible compared with EDA interaction ${ }^{37,38}$. The 2, 4-DCP adsorption on CD-MS is a Langmuir type with homogeneous binding energy. Therefore, it is assumed that $n-\pi$ EDA interaction plays more important role for the improved adsorption due to the presence of more $\mathrm{N}$ and $\mathrm{O}$ atoms. The increased capture percentage of 2, 4-DCP with the increasing $\mathrm{pH}$ value from 2-8 indicates that the deprotonation of surface silanol has a positive effect on the adsorption capacity (Figure 3b), which should be attributed to the enhanced $n-\pi$ EDA interaction between 2, 4DCP and deprotonated atoms with more $n$ electrons ( $\mathrm{O}$ and $\mathrm{N}$ ). At the $\mathrm{pH}$ value below the isotropic point of CD-MS $(\mathrm{pH}=5)$, the hydrogen- $\pi$ interaction should also be responsible for the high capture percentage. For metal ions, the capture percentages of metal ions all increase with the increasing $\mathrm{pH}$ value from 2 to 5 , which is accordant with the isoelectric point of CD-MS and attributed to the increased electrostatic interaction. The higher adsorption capacity to $\mathrm{Hg}$ (II) and $\mathrm{Cu}$ (II) should be ascribed to the contribution from a stronger complex tendency of amide group with $\mathrm{Hg}$ (II) through the formation of inner-sphere surface complex ${ }^{39}$.

\section{Competition between different metal ions}

In the tri-metal solution, the adsorptions of $\mathrm{Cu}$ (II) and $\mathrm{Pb}$ (II) show negligible variation, while the adsorption of $\mathrm{Hg}$ (II) is depressed compared to the adsorption in the isolate solution. The total metal ion concentration in the tri-metal solution is higher than that used in the isolate system since the respective concentration of $\mathrm{Hg}$ (II), $\mathrm{Cu}$ (II) and $\mathrm{Pb}$ (II) in the tri-metal system is set as the same as that in the mono-metal system. In isolate solution, $\mathrm{Pb}$ (II) is adsorbed by CD-MS mainly through the electrostatic interaction between positively charged metal ions and negatively dissociated silanols, while $\mathrm{Cu}$ (II) and $\mathrm{Hg}$ (II) are adsorbed by the extra support from amide group due to the formation of inner sphere complex. The preserved adsorption capacity of CD-MS to $\mathrm{Cu}$ (II) and $\mathrm{Pb}$ (II) in the mixed system indicates there are enough pore volume and adsorption sites to accommodate the increased amount of metal ions. The decreased adsorption of $\mathrm{Hg}$ (II) may be attributed to the occupation of the framework surface by hydrated $\mathrm{Cu}$ (II) and $\mathrm{Pb}$ (II) with large size ( 0.42 and $0.40 \mathrm{~nm}$ of radii $)^{40}$, shielding the amide groups from $\mathrm{Hg}$ (II) with smaller hydrated ion size $(0.1 \mathrm{~nm} \text { of radius })^{41}$.

\section{Influence of 2, 4-DCP to Metal and Vice Versa}

The presence of 2, 4-DCP does not cause the obvious variation of $\mathrm{Hg}$ (II) or $\mathrm{Cu}$ (II) adsorption, but a prominent increase of $\mathrm{Pb}$ (II) adsorption. The $\mathrm{Pb}$ (II) adsorption are mainly through the electrostatic interaction with negatively charged surface in the absence of 2, 4-DCP. The different effect of 2, 4-DCP addition on metal ions can only be ascribed to the complex formation between $\mathrm{Pb}$ (II) and electron-rich chlorine group on 2, 4-DCP. In the mixed metal ion-2, 4-DCP solution, the 2, 4-DCP adsorption is all depressed in the presence of different metal ions. Since the isolate adsorption of 2, 4-DCP is attributed to the formation of n$\pi$ EDA as demonstrated above, the decreased adsorption in the mixed system should be ascribed to the part shielding of amide groups from 2, 4-DCP due to the covering of hydrated metal ions. The more decreased 2, 4-DCP adsorption in the presence of $\mathrm{Cu}$ (II) or $\mathrm{Hg}$ (II) may be ascribed to the strong complexation ability of $\mathrm{Cu}$ (II) or $\mathrm{Hg}$ (II) to amide group, which is accordant with the result from the isolate adsorption (Figure 4a).

\section{Conclusion}

In this research, we reported a multi-group modified mesoporous silica through the co-condensation of TEOS and silylated CD containing amide and aromatic rings. CD-MS have compared with other silica-based adsorbents reported in recently years which shown in Table S5. It manifests that this hybrid material has high adsorption capacity both to organic 2, 4-DCP and inorganic $\mathrm{Cu}$ (II), $\mathrm{Pb}$ (II) and $\mathrm{Hg}$ (II). The adsorptions of 2, 4-DCP and metal ions follow Langmuir and Freundlich models, 
respectively, and both of them obey the pseudo-second-order kinetics. The efficient 2, 4-DCP adsorption is ascribed to the enhanced $n-\pi$ EDA interaction between 2, 4-DCP and amide group with $\mathrm{N}$ and $\mathrm{O}$ atoms. $\mathrm{Hg}$ (II) and $\mathrm{Cu}$ (II) adsorptions have more prominent improvement than $\mathrm{Pb}$ (II) adsorption through forming inner sphere complex with amide groups on CD. The comprehensive adsorption behavior of each pollutant in mixed system has been systematically studied on mesoporous silica materials for the first time. In a mixed metal ions system, the Hg (II) adsorption is much depressed due to the shielding of CD NP by other adsorbed metal ions with large hydration radius. In a mixed system of metal ion and 2, 4-DCP, the adsorption of 2, 4DCP is ubiquitously depressed due to the presence of metal ions in the order of $\mathrm{Cu}$ (II) $\approx \mathrm{Hg}$ (II) $>\mathrm{Pb}$ (II), while the $\mathrm{Pb}$ (II) adsorption is improved due to its strong complex with $\mathrm{Cl}$ group of 2, 4-DCP.

\section{Acknowledgements}

This work has been supported by the National Nature Science Foundation of China (U1407102, 21173077 and 21377038), the National Basic Research Program of China (973 Program, 2013CB632403), the Science and Technology Commission of Shanghai Municipality (14ZR1410700 and 14230710500), the Research Fund for the Doctoral Program of Higher Education (20120074130001) and the Fundamental Research Funds for the Central Universities.

\section{Notes and References}

${ }^{1}$ Key Lab for Advanced Materials and Institute of Fine Chemicals, East China University of Science and Technology, Shanghai, 200237, P. R. China

${ }^{2}$ Department of Chemistry and Laboratory of Advanced Materials, Fudan University, Shanghai 200433, P. R. China

${ }^{3}$ Centre for Materials Science, Institute of Nanotechnology and Bioengineering, School of Forensic and Investigative Sciences, University of CentralLancashire, Preston, UK

${ }^{4}$ Department of Applied Chemistry, Graduate School of Engineering, Osaka Prefecture University, Osaka 599-8531, Japan

CORRESPONDING AUTHOR: Jinlong Zhang; Fan Zhang

E-mail: jlzhang@ecust.edu.cn; zhang_fan@fudan.edu.cn

\section{References}

1. C. Kresge, M. Leonowicz, W. Roth, J. Vartuli and J. Beck, Nature, 1992, 359, 710-712.

2. J. Hu, X. Wang, L. Liu and L. Wu, J. Mater. Chem. A, 2014, 2, 19771-19777.

3. R. Serna-Guerrero and A. Sayari, Environ. Sci. Technol. 2007, 41, 4761-4766.

4. A. Walcarius and L. Mercier, J. Mater. Chem. 2010, 20, 4478-4511.

5. H. Wang, M. Tang, L. Han, J. Cao, Z. Zhang, W. Huang, R. Chen and C. Yu, J. Mater. Chem. A 2014. DOI: 10.1039/c4ta02899f.

6. W. Hertl, M. L. Hair, J. Phys. Chem. 1968, 72, (13), 4676-4682.

7. W. Teng, Z. Wu, D. Feng, J. Fan, J. Wang, H. Wei, M. Song and D. Zhao, Environ. Sci. Technol. 2013, 47, 8633-8641.

8. G. Li, Z. Zhao, J. Liu and G. Jiang, J. Hazard. Mater.2011, 192, 277283.

9. W. Huang, Y. Zhu, J. Tang, X. Yu, X. Wang, D. Li and Y. Zhang, J. Mater. Chem. A, 2014, 2, 8839-8848.

10. I. Emmanuelawati, J. Yang, J. Zhang, H. Zhang, L. Zhou and C. Yu, Nanoscale, 2013, 5, 6173-6180
11. J. Aguado, J. M. Arsuaga, A. Arencibia, M. Lindo and V. Gascón, J. Hazard. Mater. 2009, 163, 213-221.

12. M. Meng, X. Meng, Y. Liu, Z. Liu, J. Han, Y. Wang, M. Luo, R. Chen, L. Ni, Y. Yan, J. Hazard. Mater. 2014. DOI:10.1016/j.jhazmat.2014.06.002.

13. Q. Hu, J. J. Li; Z. P. Hao, L. D. Li, S. Z. Qiao, Chem. Eng. J. 2009, 149, (1-3), 281-288.

14. Y. Deng, D. Qi, C. Deng, X. Zhang and D. Zhao, J. Am. Chem. Soc., 2008, 130, 28-29.

15. X. Yang, C. Chen, J. Li, G. Zhao, X. Ren and X. Wang, RSC Adv. 2012, 2, 8821-8826.

16. F.-G. Simon and T. Meggyes, Land. Contam. Reclam. 2000, 8, 103116.

17. A.Sayari, S. Hamoudi, Y. Yang, Chem. Mater. 2005, 17, (1), 212216.

18. J. Lei, L. Yang, D. Lu, X. Yan, C. Cheng, Y. Liu, L. Wang and J. Zhang, Adv. Opt. Mater. 2014. DOI: 10.1002/adom.201400364.

19. F. Wang, Z. Xie, H. Zhang, C. y. Liu and Y. g. Zhang, Adv. Funct. Mater. 2011, 21, 1027-1031.

20. H. Zhao, K. L. Nagy, J. S. Waples, G. F. Vance, Environ. Sci. Technol. 2000, 34, (22), 4822-4827.

21. M. Anbia and M. Lashgari, Chem. Eng. J. 2009, 150, 555-560.

22. Q. Qin, K. Liu, D. Fu and H. Gao, J. Environ. Sci. 2012, 24, 14111417.

23. H.-T. Fan, X.-T. Sun, Z.-G. Zhang and W.-X. Li, J. Chem \& Eng. Data. 2014. DOI: 10.1021/je500328t.

24. B. Fotoohi and L. Mercier, Sep. Purif. Technol. 2014, 127, 84-96.

25. A. Shahbazi, H. Younesi and A. Badiei, Chem. Eng. J. 2011, 168, 505-518.

26. D. Zhao, J. Feng, Q. Huo, N. Melosh, G. H. Fredrickson, B. F. Chmelka and G. D. Stucky, Science, 1998, 279, 548-552.

27. D. Zhao, P. Yang, N. Melosh, J. Feng, B. F. Chmelka and G. D. Stucky, Adv. Mater. 1998, 10, 1380-1385.

28. A. Murashkevich, A. Lavitskaya, T. Barannikova and I. Zharskii, J. Appl. Spectrosc. 2008, 75, 730-734.

29. T. Rajh, O. I. Micic and A. J. Nozik, J. Phys. Chem. 1993, 97, 1199912003.

30. P. A. Mangrulkar, S. P. Kamble, J. Meshram, S. S. Rayalu, J. Hazard. Mater. 2008, 160, (2), 414-421.

31. D. Karpovich and G. Blanchard, Langmuir, 1994, 10, 3315-3322.

32. Z. Reddad, C. Gerente, Y. Andres and P. Le Cloirec, Environ. Sci. Technol. 2002, 36, 2067-2073.

33. M. Monier, D. Abdel-Latif, J. Hazard. Mater. 2013, 250, 122-130.

34. M. Yurdakoç, Y. Seki, S. Karahan and K. Yurdakoç, J. Colloid. Interf. Sci. 2005, 286, 440-446.

35. M. Keiluweit and M. Kleber, Environ. Sci. Technol. 2009, 43, 34213429.

36. S. K. Parida, S. Dash, S. Patel and B. Mishra, Adv. Colloid. Interf. Sci. 2006, 121, 77-110.

37. A. M. A. Moustafa, K. N. McPhedran, J. Moreira and M. Gamal ElDin, Environ. Sci. Technol. 2014, 48, 14472-14480.

38. A. Radian and Y. Mishael, Environ. Sci. Technol.2012, 46, 62286235.

39. H. P. v. Leeuwen and R. M. Town, Environ. Sci. Technol. 2008, 43, 88-93. 
40. B. Tansel, J. Sager, T. Rector, J. Garland, R. F. Strayer, L. Levine, M. Roberts, M. Hummerick and J. Bauer, Sep. Purif. Technol. 2006, 51, 40-47.

41. D. Grdenić, Q. Rev. Chem. Soc., 1965, 19, 303-328. 